\title{
The first total synthesis of the novel triquinane natural products pleurotellol and pleurotellic acid
}

\author{
Goverdhan Mehta* and A. Sai Krishna Murthy \\ Department of Organic Chemistry, Indian Institute of Science, Bangalore 560 012, India
}

\begin{abstract}
The first total synthesis of the triquinane based sesquiterpenoid antibiotics $( \pm)$-pleurotellol and ( \pm )-pleurotellic acid isolated from the fermentation broth of Pleurotellus hypnophilus have been accomplished. The triquinane based bis-enone system obtained via photo-thermal metathesis in a caged pentacyclic dione has been elaborated to the natural products through carefully crafted functional group transformations.
\end{abstract}

Natural products embodying either a linearly-fused or angularly-fused triquinane framework continue to surface in the literature at regular intervals from diverse sources like marine organisms, microbial fermentation broths and terrestrial plants. ${ }^{1}$ Among these, sesquiterpenoids based on the linearly-fused tricyclo[6.3.0.0.0.6. undecane skeleton 1 have aroused a great deal of interest on account of their skeletal and functional diversity that poses a considerable synthetic challenge. ${ }^{2}$ Five different skeletal types, differing in the disposition of the methyl groups and functionalization pattern on the basic framework 1, have been encountered so far among naturally occurring sesquiterpenoids. These are represented by coriolin 2 (hirsutane type), cucumin E 3 (isohirsutane type), ceratopicanol 4 (ceratopicane type), capnellene 5 (capnellane type) and pleurotellol $\mathbf{6}$

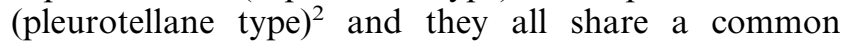
biogenetic origin emanating from the farnesyl pyrophosphate derived humulenyl cation.

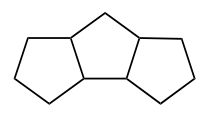

1

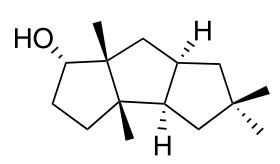

4

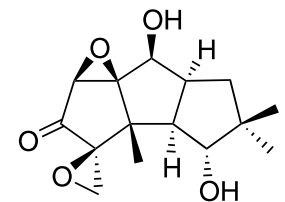

2

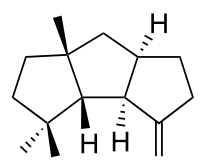

5

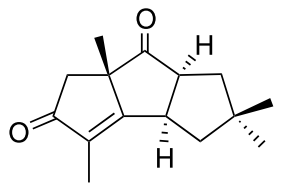

3

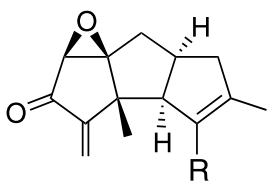

$6 \mathrm{R}=\mathrm{CH}_{2} \mathrm{OH}$

$7 \mathrm{R}=\mathrm{COOH}$
* Corresponding author. E-mail: gm@orgchem.iisc.ernet.in
In a collaborative endeavor, the research groups of Steglich and $\mathrm{Anke}^{3}$ reported the isolation and structure determination of the sesquiterpenoid antibiotics pleurotellol 6 and pleurotellic acid 7 from the mycelial cultures of Pleurotellus hypnophilus (Berc.) Sacc. (Agaricales). Structures of $\mathbf{6}$ and $\mathbf{7}$, representing a rearranged hirsutane skeleton, were deduced on the basis of NMR decoupling studies and biosynthetic considerations. ${ }^{3 \mathrm{c}}$ While syntheses of several members of the skeletal types represented by $\mathbf{2 - 5}$ have been reported in recent years, ${ }^{2,4}$ pleurotellol $\mathbf{6}$ and the related pleurotellic acid 7 have not yielded to synthesis, despite being known for nearly two decades. This in part could be attributed to the high level of functionalization present in the two peripheral five membered rings of the triquinane framework present in 6 and 7. As part of our continuing interest $\mathrm{t}^{5}$ in the synthesis of linearly fused triquinane natural products, we have now accomplished the first syntheses of pleurotellol 6 and pleurotellic acid 7 in racemic form, which also reconfirm their structural assignments. ${ }^{3 \mathrm{c}}$

For the synthesis of natural products 6 and 7, we opted for the photo-thermal metathesis based approach delineated by us sometime $\mathrm{ago}^{5 \mathrm{a}, \mathrm{b}}$ as it rapidly delivers a linear triquinane system in which the peripheral fivemembered rings are adequately functionalized for further manipulation. Pentacyclic dione $\mathbf{8}^{5 \mathrm{~b}}$ readily available from cyclopentadiene and 2,5-dimethyl- $p$-benzoquinone in two steps, served as the starting point and was elaborated to the cis, syn, cis-fused triquinane bis-enone 9 through flash vacuum pyrolysis as described earlier by us. ${ }^{5 b, f}$ Thermally induced equilibration in 9 led to the thermodynamically more stable cis, anti, cis-fused triquinane bis-enone 10 (Scheme 1). ${ }^{\text {, }}$ 


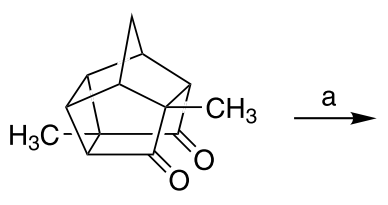

8

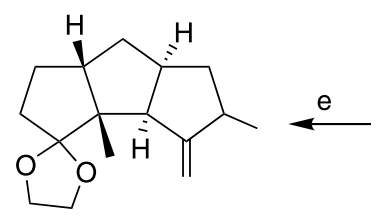

13

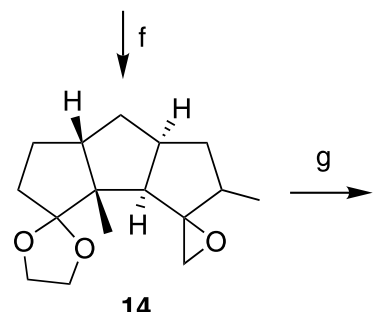

14<smiles>CC1=C[C@H]2C[C@@H]3C=CC(=O)[C@H](C)[C@]3(C)[C@H]2C(=O)C1C</smiles>

9<smiles>CC1=C[C@H]2C[C@@H]3C=CC(=O)[C@H]3[C@H]2C1=O</smiles>

10

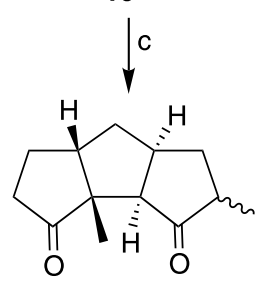

11

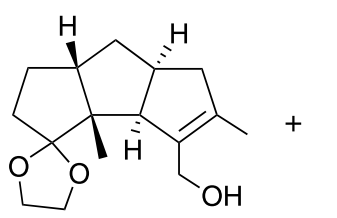

$(67: 33)$

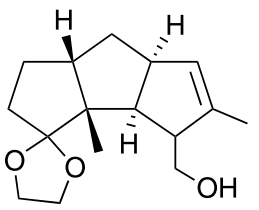

16

Scheme 1. Reagents and conditions: (a) FVP, 590-610 $\mathrm{C}, 10^{-2}$ torr, $85-90 \%$; (b) benzyl benzoate, $320^{\circ} \mathrm{C}, 20 \mathrm{~min}, 85 \%$ after three equilibration cycles; (c) $10 \% \mathrm{Pd}-\mathrm{C}, \mathrm{H}_{2}, 25$ psi, EtOAc, $5 \mathrm{~h}$, quant.; (d) ethylene glycol, CSA, benzene, reflux, 12 h, 90\%; (e) $\mathrm{PPh}_{3} \mathrm{CH}_{3} \mathrm{Br}, t \mathrm{BuO}^{-} \mathrm{K}^{+}$, THF, reflux, $8 \mathrm{~h}, 85 \%$; (f) $m \mathrm{CPBA}, \mathrm{NaHCO}_{3}, \mathrm{DCM}, 0^{\circ} \mathrm{C}-\mathrm{rt}, 30 \mathrm{~min}, 90 \%$; (g) TMSOTf, DMAP, pyridine, $0^{\circ} \mathrm{C}-\mathrm{rt}, 3 \mathrm{~h}, 80-85 \%$ overall $(57 \%$ of $\mathbf{1 5}$ and $28 \%$ of $\mathbf{1 6})$.

Catalytic hydrogenation of $\mathbf{1 0}$ to $\mathbf{1 1}$ and further regioselective mono-ketalization led to $\mathbf{1 2}$, in which the two carbonyl groups were differentiated and the carbonyl group next to the quaternary center had been protected (Scheme 1). ${ }^{6}$ Wittig olefination in 12 was smooth and delivered the methylenecyclopentane derivative $\mathbf{1 3}^{6}$ quite uneventfully. The key allylic alcohol functionality of the natural product was sought to be generated from 13 through an epoxidation and ring opening protocol. Epoxidation of the terminal olefinic bond in 13 with $m$-chloroperbenzoic acid furnished a single spiro-epoxide $\mathbf{1 4}$ in good yield (Scheme 1). TMSOTf mediated opening of the epoxide ring in $\mathbf{1 4}$ under conditions that favor the formation of allylic alcohols led to a 2:1 mixture of $\mathbf{1 5}$ and $\mathbf{1 6}$ in which the desired alcohol $\mathbf{1 5}$ was the major product (Scheme 1). The two tricyclic alcohols $\mathbf{1 5}$ and $\mathbf{1 6}$ were separated through silica gel column chromatography and were fully characterized. ${ }^{6}$ Concurrent formation of $\mathbf{1 6}$ through double bond isomerization was indicative of the sterically encumbered nature of the tetrasubstituted cyclopentene moiety present in $\mathbf{1 5}$ and natural products 6 and 7. Indeed, we observed that epoxide 14 when exposed to a variety of Lewis or protic acid catalysts exhibited marked propensity towards the formation of the ring-opened product with double-bond migration to the less substituted position as in $\mathbf{1 6}$.

With the functionalization in one of the five membered rings secured, attention was turned towards building-up the more complex epoxy-cyclopentadienenone pattern in the other peripheral five membered ring. Protection of the primary hydroxyl group in $\mathbf{1 5}$ as the methoxymethyl derivative also resulted in ketal deprotection and led to the cyclopentanone derivative $\mathbf{1 7}$ (Scheme 2). ${ }^{6}$ Wittig olefination furnished the exo-methylene compound 18. Allylic oxidation in $\mathbf{1 8}$ with excess selenium dioxide directly delivered the enone $19^{6}$ through the intermediacy of the corresponding allylic alcohol whose formation was also observed when the reaction was intercepted before full conversion to $\mathbf{1 9}$ (Scheme 2). The dienone moiety was generated following the Saegusa procedure ${ }^{7}$ involving formation of TMS-enol ether and palladium mediated oxidative dehydrosilylation to furnish 20 (Scheme 2). At this stage, the relatively straightforward looking deprotection of the MOM protective group in $\mathbf{2 0}$ proved to be quite cumbersome due to the migration of the tetrasubstituted double bond (vide supra) to the less substituted position (cf. 16) and only after many trials could conditions be devised to deliver 21 satisfactorily. Lastly, exposure of tricyclic dienone $\mathbf{2 1}$ to hydrogen peroxide in a basic medium delivered pleurotellol $\mathbf{6}$, which was found to be spectroscopically (IR, ${ }^{1} \mathrm{H}$ and ${ }^{13} \mathrm{C}$ NMR) identical with the natural product. ${ }^{6}$ Since, pleurotellol 6 has already been converted to pleurotellic acid $7,{ }^{3 \mathrm{c}}$ our synthesis of $\mathbf{6}$ also constitutes a formal synthesis of $\mathbf{7}$.

In summary, we have achieved a total synthesis of the novel triquinane based sequiterpenoid antibiotics $( \pm)$ pleurotellol 6 and $( \pm$ )-pleurotellic acid 7, following an adaptation of the versatile photo-thermal metathesis based approach to linearly fused tricyclopentanoids. Installation of the sensitive functionalization pattern in 


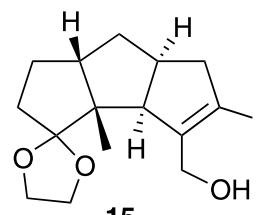

15<smiles>C=C1C(=O)C=C2C[C@H]3CC(C)=C(CO)[C@H]3[C@]12C</smiles>

21

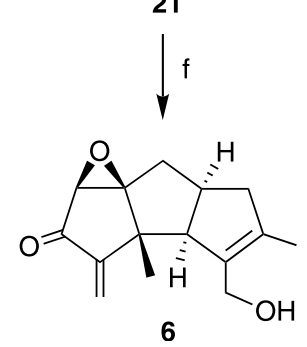

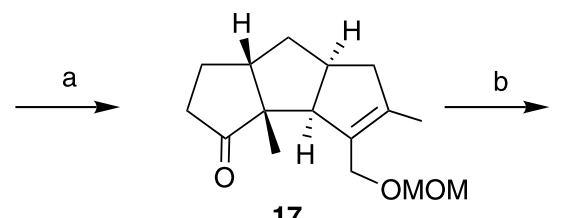

17

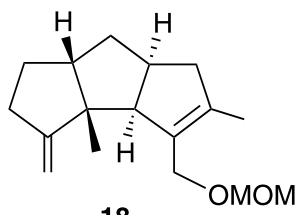

18

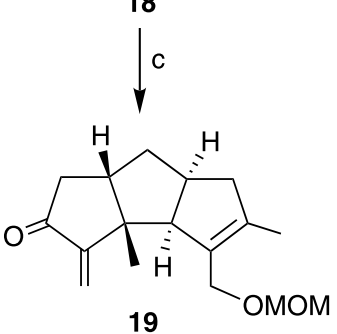

20

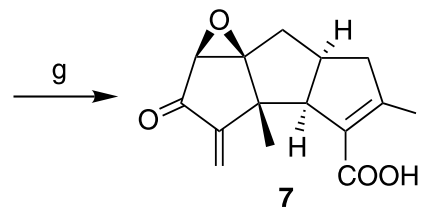

Scheme 2. Reagents and conditions: (a) $\mathrm{MOMCl}, \mathrm{Et}_{3} \mathrm{~N}, \mathrm{DCM}, 0^{\circ} \mathrm{C}-\mathrm{rt}, 4 \mathrm{~h}, 75 \%$; (b) $\mathrm{PPh}_{3} \mathrm{CH}_{3} \mathrm{Br},{ }^{t} \mathrm{BuO}^{-} \mathrm{K}^{+}, \mathrm{THF}, \mathrm{rt}, 6-8 \mathrm{~h}, 80 \%$; (c) $\mathrm{SeO}_{2}$, TBHP, DCM, rt, 6-8 h, 85\%; (d) (i) LDA, THF, DMPU, TMSCl, $-10^{\circ} \mathrm{C}, 6 \mathrm{~h}$; (ii) $\mathrm{Pd}(\mathrm{OAc})_{2}, \mathrm{CH}_{3} \mathrm{CN}, \mathrm{rt}, 5 \mathrm{~h}, 50 \%$; (e) isopropyl alcohol, conc. $\mathrm{HCl}, 55^{\circ} \mathrm{C}, 10 \mathrm{~h}, 80 \%$; (f) $30 \% \mathrm{H}_{2} \mathrm{O}_{2}, \mathrm{~K}_{2} \mathrm{CO}_{3}, \mathrm{H}_{2} \mathrm{O}, \mathrm{DCM}, 0^{\circ} \mathrm{C}-\mathrm{rt}, 12 \mathrm{~h}, 50 \%$ conversion; (g) $\mathrm{Ref}$. $3 \mathrm{c}$.

the two peripheral five-membered rings of the triquinane system through short and simple reaction sequences is the other notable feature of our synthesis.

\section{Acknowledgements}

We thank Professor W. Steglich for providing the comparison spectra of pleurotellol. A.S.K. thanks Indian Institute of Science for the award of a Research Associateship. This research was also supported by the CBU of JNCASR, Bangalore. We also acknowledge the preliminary experiments carried out by Dr. A. Narayana Murty towards the total synthesis of pleurotellol.

\section{References}

1. For the latest entrant to the triquinane based natural products family, see: Roncal, T.; Cordobes, S.; Ugalde, U.; He, Y.; Sterner, O. Tetrahedron Lett. 2002, 43, 6799.

2. Recent reviews: (a) Mehta, G.; Srikrishna, A. Chem. Rev. 1997, 97, 671; (b) Singh, V.; Thomas, B. Tetrahedron 1998, 54, 3647.

3. (a) Kupka, J.; Anke, T.; Giannetti, B.-M.; Steglich, W. Arch. Mikrobiol. 1981, 130, 223; (b) Steglich, W. Pure Appl. Chem. 1981, 53, 1233; (c) Giannetti, B.-M.; Steffan, B.; Steglich, W.; Kupka, J.; Anke, T. Tetrahedron 1986, 42, 3587.

4. For some of the recent accomplishments in the area of linear triquinane natural product syntheses from other groups, see: (a) Singh, V.; Vedantham, P.; Sahu, P. K. Tetrahedron Lett. 2002, 43, 519; (b) Mukai, C.; Kobayashi,
M.; Kim, I. J.; Hanaoka, M. Tetrahedron 2002, 58, 5225; (c) Shindo, M.; Sato, Y.; Shishido, K. Tetrahedron Lett. 2002, 43, 5039; (d) Harrowven, D. C.; Lucas, M. C.; Howes, P. D. Tetrahedron 2001, 57, 9157.

5. (a) Mehta, G.; Reddy, A. V.; Srikrishna, A. Tetrahedron Lett. 1979, 20, 4863; (b) Mehta, G.; Srikrishna, A.; Reddy, A. V.; Nair, M. S. Tetrahedron 1981, 37, 4543; (c) Mehta, G.; Reddy, A. V. J. Chem. Soc., Chem. Commun. 1981, 756; (d) Mehta, G.; Reddy, A. V.; Murty, A. N.; Reddy, D. S. J. Chem. Soc., Chem. Commun. 1982, 540; (e) Mehta, G.; Reddy, D. S.; Murty, A. N. J. Chem. Soc., Chem. Commun. 1983, 824; (f) Mehta, G.; Murthy, A. N.; Reddy, D. S.; Reddy, A. V. J. Am. Chem. Soc. 1986, 108, 3443; (g) Mehta, G.; Karra, S. R. J. Chem. Soc., Chem. Commun. 1991, 1367; (h) Mehta, G.; Umarye, J. D. Tetrahedron Lett. 2001, 42, 1991; (i) Mehta, G.; Murthy, A. S. K.; Umarye, J. D. Tetrahedron Lett. 2002, 43, 8301.

6. All new compounds reported here were racemic and characterized on the basis of spectroscopic data (IR, ${ }^{1} \mathrm{H}$ and ${ }^{13} \mathrm{C}$ NMR and mass). Spectral data for some of the key compounds follows. 14: ${ }^{1} \mathrm{H}$ NMR $\left(300 \mathrm{MHz}, \mathrm{CDCl}_{3}\right): \delta$ $3.91-3.83(\mathrm{~m}, 4 \mathrm{H}), 3.02(\mathrm{~d}, J=4.8 \mathrm{~Hz}, 1 \mathrm{H}), 2.89-2.77$ (m, $2 \mathrm{H}), 2.34(\mathrm{~d}, J=10.2 \mathrm{~Hz}, 1 \mathrm{H}), 2.24-2.11(\mathrm{~m}, 2 \mathrm{H}), 1.91-$ $1.44(\mathrm{~m}, 7 \mathrm{H}), 1.31-1.24(\mathrm{~m}, 1 \mathrm{H}), 0.96(\mathrm{~s}, 3 \mathrm{H}), 0.74(\mathrm{~d}$, $J=6.6 \mathrm{~Hz}, 3 \mathrm{H}) ;{ }^{13} \mathrm{C}$ NMR $\left(75 \mathrm{MHz}, \mathrm{CDCl}_{3}\right): \delta 120.66$, $67.95,65.19,64.63,57.13,55.96,50.81,47.92,40.70,39.15$, $38.10,35.0,33.33,25.48,15.68,11.25 .15:{ }^{1} \mathrm{H}$ NMR $(300$ $\left.\mathrm{MHz}, \mathrm{CDCl}_{3}\right): \delta 4.25(1 / 2 \mathrm{ABq}, J=13.5 \mathrm{~Hz}, 1 \mathrm{H}), 4.07$ $(1 / 2 \mathrm{ABq}, J=13.5 \mathrm{~Hz}, 1 \mathrm{H}), 4.02-3.93(\mathrm{~m}, 4 \mathrm{H}), 3.42(\mathrm{~d}$, $J=9.9 \mathrm{~Hz}, 1 \mathrm{H}), 2.99-2.92(\mathrm{~m}, 1 \mathrm{H}), 2.57-2.48(\mathrm{~m}, 1 \mathrm{H})$, 2.25-2.18 (m, 1H), 2.09-2.03 (m, 2H), 1.93-1.73 (m, 3H), 1.62 (s, 3H), $1.55-1.32$ (m, 2H), 0.81 (s, 3H); ${ }^{13} \mathrm{C}$ NMR (75 $\left.\mathrm{MHz}, \mathrm{CDCl}_{3}\right): \delta 134.74(2 \mathrm{C}), 121.36,65.02,64.30,59.32$, 57.13 (2C), 53.10, 46.68, 39.77, 38.69, 34.16, 25.84, 15.07, 
13.96. 16: ${ }^{1} \mathrm{H}$ NMR $\left(300 \mathrm{MHz}, \mathrm{CDCl}_{3}\right): \delta 5.32(\mathrm{~s}, 1 \mathrm{H})$, $3.96-3.76(\mathrm{~m}, 5 \mathrm{H}), 3.41-3.24(\mathrm{~m}, 3 \mathrm{H}), 2.72-2.55(\mathrm{~m}, 2 \mathrm{H})$, $2.21-2.03(\mathrm{~m}, 2 \mathrm{H}), 1.89-1.74(\mathrm{~m}, 3 \mathrm{H}), 1.62(\mathrm{~s}, 3 \mathrm{H}), 1.47-1.30$ $(\mathrm{m}, 2 \mathrm{H}), 0.90(\mathrm{~s}, 3 \mathrm{H}) ;{ }^{13} \mathrm{C} \mathrm{NMR}\left(75 \mathrm{MHz}, \mathrm{CDCl}_{3}\right): \delta 137.95$, $130.23,121.66,66.78,64.86,64.68,55.66,53.67,52.44$, 51.80, 49.58, 37.29, 34.61, 26.09, 15.69, 14.95. 19: ${ }^{1} \mathrm{H}$ NMR $\left(300 \mathrm{MHz}, \mathrm{CDCl}_{3}\right) \delta 6.04(\mathrm{~s}, 1 \mathrm{H}), 5.29(\mathrm{~s}, 1 \mathrm{H}), 4.644 .58$ $(\mathrm{m}, 2 \mathrm{H}), 4.27(1 / 2 \mathrm{ABq}, J=11.2 \mathrm{~Hz}, 1 \mathrm{H}), 4.0(1 / 2 \mathrm{ABq}$, $J=11.2 \mathrm{~Hz}, 1 \mathrm{H}), 3.37$ (s, 3H), $3.26(\mathrm{~d}, J=8.7 \mathrm{~Hz}, 1 \mathrm{H})$, 2.92-2.90 (m, 1H), 2.59-2.14 (m, 5H), 1.77-1.62 (m, 2H), $1.73(\mathrm{~s}, 3 \mathrm{H}), 1.07(\mathrm{~s}, 3 \mathrm{H}) ;{ }^{13} \mathrm{C}$ NMR $\left(75 \mathrm{MHz}, \mathrm{CDCl}_{3}\right): \delta$ 207.74, 155.35, 139.89, 131.96, 116.76, 95.93, 63.38, 61.49, 55.37, 54.78, 47.59, 46.04, 41.44, 41.39, 37.24, 22.57, 14.08 . 20: ${ }^{1} \mathrm{H}$ NMR $\left(300 \mathrm{MHz}, \mathrm{CDCl}_{3}\right): \delta 6.02(\mathrm{~s}, 1 \mathrm{H}), 5.95(\mathrm{~s}, 1 \mathrm{H})$, 5.47 (s, 1H), 4.66-4.61 (m, 2H), $4.29(1 / 2 \mathrm{ABq}, J=11.1 \mathrm{~Hz}$, $1 \mathrm{H}), 4.09(1 / 2 \mathrm{ABq}, J=11.1 \mathrm{~Hz}, 1 \mathrm{H}), 3.38(\mathrm{~s}, 3 \mathrm{H}), 2.99-2.93$ $(\mathrm{m}, 3 \mathrm{H}), 2.79-2.70(\mathrm{~m}, 1 \mathrm{H}), 2.43-2.31(\mathrm{~m}, 2 \mathrm{H}), 1.79(\mathrm{~s}, 3 \mathrm{H})$, 1.05 (s, 3H); ${ }^{13} \mathrm{C} \mathrm{NMR}\left(75 \mathrm{MHz}, \mathrm{CDCl}_{3}\right): \delta 197.89,189.57$,
$152.80,142.04,130.54,123.59,114.62,95.67,62.82,58.48$, 55.52, 53.97, 47.47, 40.83, 33.61, 22.07, 14.21. 6: ${ }^{1} \mathrm{H}$ NMR $\left(300 \mathrm{MHz}, \mathrm{CDCl}_{3}\right): \delta 6.19(\mathrm{~s}, 1 \mathrm{H}), 5.52(\mathrm{~s}, 1 \mathrm{H}), 4.32(1 / 2$ $\mathrm{ABq}, J=12 \mathrm{~Hz}, 1 \mathrm{H}), 4.12(1 / 2 \mathrm{ABq}, J=12 \mathrm{~Hz}, 1 \mathrm{H}), 3.47$ (s, $1 \mathrm{H}), 3.05-2.69(\mathrm{~m}, 3 \mathrm{H}), 2.17-2.12(\mathrm{~m}, 2 \mathrm{H}), 1.76(\mathrm{~s}, 3 \mathrm{H}), 1.69$ (s, 1H), 1.08 (s, 3H); $\left.{ }^{13} \mathrm{C} \mathrm{NMR} \mathrm{(75} \mathrm{MHz,} \mathrm{CDCl}_{3}\right): \delta 198.07$, $151.88,139.94,133.05,121.68,76.29,60.86,58.76,58.63$, 48.25, 47.92, 35.79, 30.74, 15.86, 13.98; HRMS (ES, $70 \mathrm{eV})$ : calcd for $\mathrm{C}_{15} \mathrm{H}_{18} \mathrm{O}_{3}\left(\mathrm{M}^{+}+\mathrm{Na}\right)$ : 269.1154; found: 269.1164 . For comparison purposes, the spectral data reported ${ }^{3 \mathrm{c}}$ for the natural product are reproduced here: ${ }^{1} \mathrm{H}$ NMR $(90$ $\left.\mathrm{MHz}, \mathrm{CDCl}_{3}\right): \delta 6.20(\mathrm{~s}, 1 \mathrm{H}), 5.63(\mathrm{~s}, 1 \mathrm{H}), 4.31$ (1/2 ABq, $1 \mathrm{H}), 4.11(1 / 2 \mathrm{ABq}, 1 \mathrm{H}), 3.46(\mathrm{~s}, 1 \mathrm{H}), 1.75(\mathrm{~s}, 3 \mathrm{H}), 1.74(\mathrm{~s}$, 1H), $1.60(\mathrm{~s}, 1 \mathrm{H}), 1.09(\mathrm{~s}, 3 \mathrm{H}) ;{ }^{13} \mathrm{C} \mathrm{NMR}(22.5 \mathrm{MHz}$, $\left.\mathrm{CDCl}_{3}\right): \delta 151.9,139.7,133.1,121.6,76.5,60.9,58.8,58.5$, 48.2, 47.9, 35.8, 30.7, 15.9, 13.9.

7. (a) Ito, Y.; Hirao, T.; Saegusa, T. J. Org. Chem. 1978, 43, 1011; (b) Mehta, G.; Sreenivas, K. Synlett 1999, 555. 